\title{
High impact weather and cyclones simultaneity in Catalonia
}

\author{
J. Campins ${ }^{1}$, M. Aran ${ }^{2}$, A. Genovés ${ }^{1}$, and A. Jansà ${ }^{1}$ \\ ${ }^{1}$ Centro Meteorológico Territorial en Illes Balears, Instituto Nacional de Meteorología, Spain \\ ${ }^{2}$ Servei Meteorològic de Catalunya, Barcelona, Spain
}

Received: 28 February 2007 - Revised: 6 June 2007 - Accepted: 16 September 2007 - Published: 19 September 2007

\begin{abstract}
The Western Mediterranean in general and Catalonia in particular are usually affected by high impact weather (HIW) events, mainly heavy rain (HR) and strong wind (SW). The improvement in the understanding and the accurate forecast of such events are major concerns for the meteorologists of the region. In the present study, HR and SW events in Catalonia are cross-referenced with an objective cyclone database for a 9-year period (from June 1995 to May 2004). Results show that in most of the HR events a cyclone is located close to Catalonia, in such a way that the feeding of a moist flow to the affected region was favoured. These cyclones can be either shallow and weak or deep and intense. A simultaneous cyclone also appears to be connected with many SW events. However, other SW events seem to be related to meso-scale circulations and, as a result, not always well captured in the cyclone database. Finally, coincident HR and SW events are analysed. In almost all of such events a deep cyclone is located in the vicinity of Catalonia.
\end{abstract}

\section{Introduction}

The Mediterranean basin is quite frequently affected by sudden events of high impact weather (HIW hereafter), often producing important damages. It is widely accepted that a large portion of such events are related to cyclones (Jansà et al., 2001; Romero et al., 1999; Horvath et al., 2006; Buzzi et al., 2003). The MEDEX (Mediterranean Experiment on Cyclones that produce High Impact Weather) is devoted to deepen into the aforementioned relationship in order to improve their forecast. Thus, in the MEDEX framework (http://medex.inm.uib.es) some cyclone catalogues and calendars of HIW are collected. Therefore, the relationship between cyclones and HIW could be obtained by means a

Correspondence to: J. Campins

(campins.pma@inm.es) cross-referencing of both databases. This was already performed for the Balearics Islands (Campins et al., 2006a) and the present work is devoted to investigate that relation for Catalonia, a larger region, located in the north-east corner of the Iberian peninsula. Catalonia region is framed in all the figures.

The complex orography of Catalonia, which main features is the Pyrenees mountain range, and the presence of the Mediterranean Sea play a determinant role in the generation of HR and SW in such region. The orographic interaction of the atmospheric flow with the Pyrenees could produce, among other effects, strong local winds (Bougeault et al., 1997). Moreover, this orographic interaction favours the generation of convergence zones which could also act as a trigger mechanism for local convection (Pascual and Callado, 2002). The orography can also act as a triggering mechanism by means of the upslope lifting. The Mediterranean Sea is a continuous source of moist and warm air (specially in autumn).

\section{Data and methodology}

The cyclone database is an objective catalogue of low-pressure centres derived from the HIRLAM(INM)$0.5^{\circ}$ smoothed analyses at 00:00, 06:00, 12:00 and 18:00 UTC , for a 9-year period (from June 1995 to may 2004) and for the Western Mediterranean. Each low-pressure centre is detected on mean sea level pressure fields, and tracked along its lifecycle. Furthermore each centre is vertically tracked and three dimensionally described by a set of variables (see Campins et al., 2006b for a detailed description of such database).

The HIW event database is composed by all the HR events (from June 1995 to May 2004) and all the SW (from December 1996 to May 2004) registered in Catalonia. Both

Published by Copernicus Publications on behalf of the European Geosciences Union. 
databases (cyclones and HIW) are available at the MEDEX web site (http://medex.inm.uib.es).

A day is considered as a HR event if a threshold of precipitation of $60 \mathrm{~mm}$ in $24 \mathrm{~h}$ is overcome in at least one pluviometric station. For the study period up to 360 events are recorded, that is, $10.9 \%$ of the days. The seasonal distribution reveals that although HR events can be registered at any season, most of them occur in autumn and in summer (33.6 and $28.3 \%$ respectively). However, some differences between both seasons can be underlined. In summer, HR is registered in a few stations and then, it is largely associated to local convection. On the contrary, in autumn the precipitation is more spread, with an elevated concentration along the coast.

Due to the complex orography, two local winds, Tramontane and Mestral, are the most frequent and the most intense winds in Catalonia. Tramontane is a northerly wind which flows in the northeasternmost coast of Catalonia, at the Pyrenees border (Campins et al., 1995). Mestral, sometimes also called Cierzo, is a northwesterly wind which flows along the Ebro valley up to the Mediterranean Sea (Riosalido et al., 1986). In order to define a SW event, two different thresholds are defined: $\geq 18 \mathrm{~m} / \mathrm{s}$ for sustained wind and $\geq 25 \mathrm{~m} / \mathrm{s}$ for wind gusts. However, as a result of the dominant character of the aforementioned local winds, both thresholds are increased up to $\geq 25 \mathrm{~m} / \mathrm{s}$ (for sustained winds) and $\geq 33 \mathrm{~m} / \mathrm{s}$ (for gusts) in their area of influence. The seasonal distribution of SW shows that most of the events are produced in winter $(35.6 \%)$, while the lowest number of events are registered in summer $(13.9 \%)$.

Finally, a third set of HIW events will be cross-referenced with the cyclone database: those events that registered HR and SW on the same day. For the common study period up to 64 events are registered (that is $2.3 \%$ of the days). HR-SW events are present along the whole year, specially in autumn $(31.2 \%)$.

In spite of the well-known relationship between cyclones and HIW, to relate a particular cyclone to a heavy rain or a strong wind event in an objective way is not a trivial task. Hence, before cross-referencing the HIW and the cyclone databases, a criterion has to be defined to choose the most related cyclone, if any. For HR events, the presence of a cyclone, even small and weak, usually favours a warm and moist flow to feed heavy precipitation. Furthermore, cyclone induced low-level convergence, which could act as a trigger mechanism. Thus, it seems that the proximity of the cyclone to the affected region is a key-feature, rather than other (as the intensity or thickness). For that reason, for HR events the closest cyclone (in terms of the distance $d$ of its centre to Catalonia) is selected. To avoid wrong matches, cyclones located far away $(d>600 \mathrm{~km})$ are rejected.

On the contrary for SW events, the cyclone distance could be not always the most relevant aspect and the cyclone intensity has obviously to be taken into account. The cyclone intensity is measured by means of the geostrophic circulation (GC), as

$\mathrm{GC}=\iint_{A} \zeta_{g} d A$

where $\zeta_{g}$ is the geostrophic vorticity and $A$ the cyclone horizontal domain (see the Appendix in Campins et al., 2006b).

However, if the strongest cyclone is chosen, some cyclones located far away could be wrongly related to SW (only the large and intense ones could be related to SW). Finally, a criterion that combines both the cyclone intensity and the proximity, by weighting the intensity with the ratio between the cyclone radius $(R)$ and the distance to the SW affected region $(d)$, is adopted (see Eq. 2).

$\mathrm{GC}^{\prime}= \begin{cases}\mathrm{GC} ; & d \leq R \\ \frac{R}{d} \mathrm{GC} ; & d>R\end{cases}$

Thus the most intense (weighted value, GC') cyclone was selected. However, to avoid weak cyclones, which are not able to produce strong wind, a threshold value must be imposed. A large value of GC' would selected only very strong lows, and hence other possible related cyclones would be excluded. On the contrary a small value of GC' would highly increase the number of simultaneous lows, but many wrong matches would be also included. After several attempts a value of $\mathrm{GC}^{\prime}=3 \times 10^{7} \mathrm{~m}^{2} \mathrm{~s}^{-1}$ was chosen.

For HR-SW events the same criteria as for HR is used. Similar results would be obtained if the SW criteria was used (not shown).

Finally we want to explore to which extend the cyclones simultaneous to HIW events are similar/different to other cyclones that also affect to Catalonia, but they are not usually linked to HIW events. To do that, the closest cyclone to Catalonia is looked for along the whole HR study period (i.e. all the days from 1 June 1996 to 31 May 2004). Similarly, the most intense cyclone (weighted value, GC') is looked for along the SW period (i.e. from 1 December 1996 to 31 May 2004). Results are referred in the text as SP-HR and SP-SW respectively.

\section{Results}

\subsection{Heavy rain and cyclones}

In most of the HR events $(77.5 \%)$ a cyclone is found near Catalonia (i.e. at a distance $d \leq 600 \mathrm{~km}$ ). The preferred location of such lows is south of Catalonia (see top panel of Fig. 1), favouring the entrance of a moist flow from the Mediterranean Sea. On the contrary, if the closest cyclone is considered for the whole study period the simultaneity frequency is reduced to $56.9 \%$. These simultaneous cyclones are located in similar regions as those simultaneous to HR events (see bottom panel of Fig. 1). 
Table 1. Frequency (\%) of cyclones per thickness for simultaneous cyclones to different datasets of events. A cyclone is considered as shallow if it extends up to $850 \mathrm{hPa}$, middle up to $500 \mathrm{hPa}$ and deep up to $300 \mathrm{hPa}$.

\begin{tabular}{lccc}
\hline & Shallow & Middle & Deep \\
\hline HR & 38.7 & 9.3 & 52.0 \\
SP-HR & 56.1 & 9.1 & 34.8 \\
SW & 22.5 & 9.9 & 67.6 \\
SP-SW & 30.7 & 10.6 & 58.7 \\
HR-SW & 21.4 & 7.1 & 71.5 \\
\hline
\end{tabular}

As Tables 1 and 2 show, main features of cyclones simultaneous to HR events are quite similar to those simultaneous to the set of events for the whole study period (SP-HR). However, some differences can be underlined: cyclones simultaneous to HR events are more intense and larger, and especially with higher potential instability than for SP-HR ones. Moreover, cyclones simultaneous to HR events are mainly deep. On the contrary for the whole study period cyclones are mainly shallow.

In spite of the high frequency of simultaneity between cyclones and HR events, in an appreciable portion of HR events no cyclone was found close to Catalonia (22.5\%). After a brief analysis of such events some possibilities can be underlined. Firstly, in some cases an intense and large cyclone, located far away from Catalonia could be related to HR. Intense Atlantic cyclones induce a southerly flow over Catalonia, and sometimes related to HR events (Llasat, 1991). Secondly, in other cases a trough (that is maximum of vorticity) is present at low levels, but not a closed low-pressure centre. A typical example is the Algerian trough, which induces an easterly flow over the Spanish Eastern Mediterranean coast, sometimes related to HR in those regions. A particularly intense event that affected Catalonia was registered during the 21 to 24 October 2000. Total accumulated rainfall higher than $500 \mathrm{~mm}$ was registered at some locations (see Homar et al., 2002). Finally, in some events neither cyclone nor pressure trough was observed and possibly these HR events are related to small-scale phenomena not well captured by the analyses at the used resolution.

\subsection{Strong wind and cyclones}

For many strong wind events registered in Catalonia a simultaneous cyclone is found ( $64 \%$ of the events). These simultaneous cyclones are located preferably at the south of Catalonia, and in a spread area that comprises the gulf of Genoa and the surrounding sea (see top panel of Fig. 2). On the contrary, for the whole study period only $38.8 \%$ of the events overcome the intensity threshold, although these cyclones are located in similar regions that those related to SW events (see bottom panel of Fig. 2).
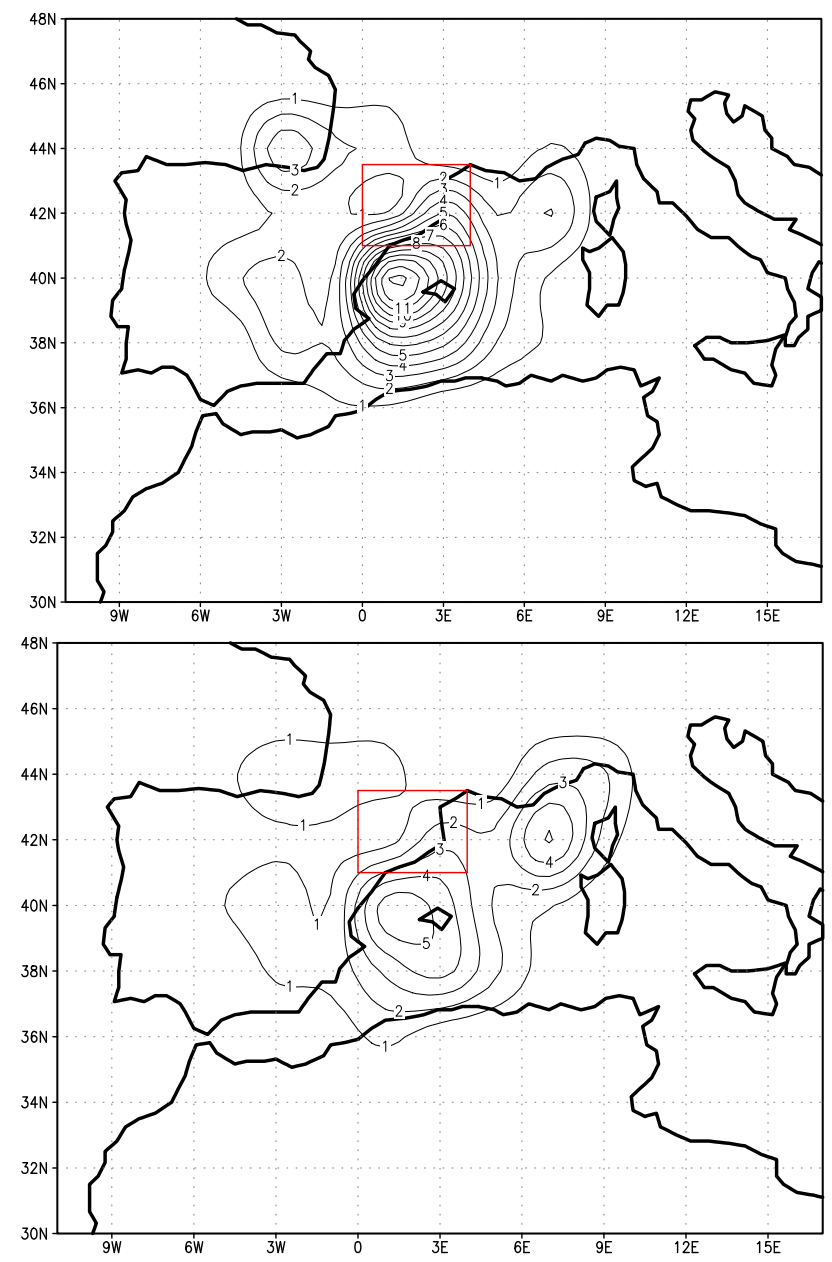

Fig. 1. Top panel: relative frequency (in $2^{\circ} \times 2^{\circ}$ latitude-longitude boxes) of the closest cyclone simultaneous to HR events. Bottom panel: as top panel for SP-HR events. Contour interval: $1 \%$.

Cyclones simultaneous to SW events are, in general large, deep and intense lows, with strong pressure gradients, though at the south of Catalonia some shallow and non-intense cyclones are found. On the contrary, cyclones which overcame the criteria for the whole study period are not as large as those simultaneous to SW events. Furthermore, the frequency of deep cyclones decreases (see Tables 1 and 2).

As an example, the cyclone of the IOP 15 of the Mesoscale Alpine Program (MAP), developed from the 6 to 9 November 1999, can be mentioned. On the 6th, an orographic cyclone formed at the south of the Alps, which intensified rapidly, as well as it progressed south-easterly along the Tyrrhenian Sea (see Buzzi et al., 2003). From the 6th to the 9th strong northerly winds were measured at several stations of Catalonia (as well as other regions like the Balearics). This cyclone was very intense, and overcame the intensity threshold, even at the end of the event when it was located very far from Catalonia. 
Table 2. Mean values of some parameters at low (L) and medium (M) or upper (U) levels for simultaneous cyclone to different datasets of events. $\zeta_{g}$ : geostrophic vorticity $\left(10^{-6} \mathrm{~s}^{-1}\right)$, GC: geostrophic circulation $\left(10^{7} \mathrm{~m}^{2} \mathrm{~s}^{-1}\right), R$ : radius $(\mathrm{km}), \nabla^{2} T$ : laplacian of temperature $\left(10^{-6} \mathrm{C} \mathrm{km}^{-2}\right), \mathrm{RH}$ : relative humidity $(\%), V$ : wind speed $\left(\mathrm{ms}^{-1}\right)$ and $\sigma_{e}$ : moist static stability $\left(10^{-7} \mathrm{~m}^{4} \mathrm{~s}^{2} \mathrm{~g}^{-2}\right)$.

\begin{tabular}{lccccccccccccc}
\hline & $\zeta_{g}$ & $\zeta_{g}$ & $\mathrm{GC}$ & $\mathrm{GC}$ & $R$ & $R$ & $\nabla^{2} T$ & $\nabla^{2} T$ & $\mathrm{RH}$ & $\mathrm{RH}$ & $V$ & $V$ & $\sigma_{e}$ \\
\hline & $\mathrm{L}$ & $\mathrm{U}$ & $\mathrm{L}$ & $\mathrm{U}$ & $\mathrm{L}$ & $\mathrm{U}$ & $\mathrm{L}$ & $\mathrm{M}$ & $\mathrm{L}$ & $\mathrm{M}$ & $\mathrm{L}$ & $\mathrm{U}$ & $1000-850$ \\
\hline HR & 55.7 & 110.1 & 3.4 & 11.3 & 435 & 555 & -40.9 & 18.6 & 72 & 59 & 7.2 & 23.3 & -3.6 \\
SP-HR & 53.4 & 106.0 & 2.9 & 10.9 & 406 & 547 & -50.4 & 20.4 & 67 & 55 & 6.6 & 22.5 & -2.1 \\
SW & 67.3 & 124.1 & 5.7 & 14.4 & 514 & 590 & -36.3 & 20.7 & 76 & 60 & 9.1 & 25.0 & -2.4 \\
SP-SW & 61.8 & 115.8 & 5.1 & 13.4 & 510 & 587 & -37.7 & 18.4 & 73 & 59 & 8.3 & 23.8 & -2.3 \\
HR-SW & 66.0 & 120.2 & 4.3 & 11.0 & 447 & 511 & -28.7 & 16.7 & 75 & 62 & 8.8 & 24.7 & -3.4 \\
\hline
\end{tabular}
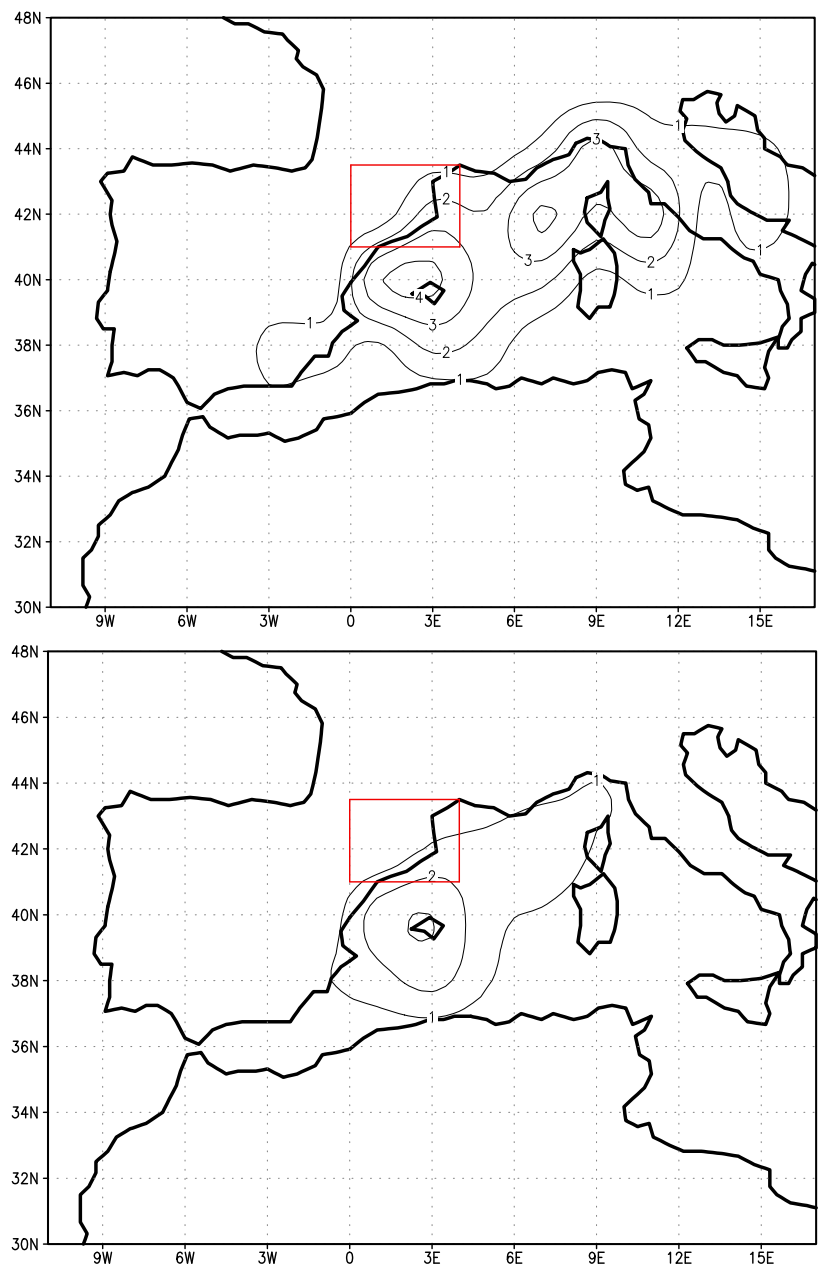

Fig. 2. Top panel: relative frequency (in $2^{\circ} \times 2^{\circ}$ latitude-longitude boxes) of the most intense (weighted value, see text) cyclone simultaneous to SW events. Bottom panel: as top panel for SP-SW events. Contour interval: $1 \%$.

For the $36 \%$ of SW events no cyclone is found (that means, for the present cyclone database and the aforementioned cri- terion). A study of many of those cases outlined two possible reasons: i) in the most frequent one, $\mathrm{SW}$ is generated by the orographic interaction of the atmospheric flow with the Pyrenees, that is, by local winds, and ii) SW was due to a very intense low pressure centre, although very far from Catalonia (usually at the Atlantic and out of the study domain).

The orographic interaction of the atmospheric flow with a mountain range produces, among other effects, local winds and a dipolar structure at both sides of the range (high pressure at the windward and low at the lee side). As for the Pyrenees, the pressure dipole is well correlated with local winds (Bessemoulin al., 1993), the presence of a lee cyclone could be used as a proxy to deduce the presence of (strong) local winds. But, the orographic low at the lee of the Pyrenees is a mesoscale structure $(100-200 \mathrm{~km})$, which is not detected in the present cyclone database. However another cyclone database, similar to the present one (that is for the same model, area and study period), but composed of nonsmoothed analyses, is able to detected such lows (see Picornell et al., 2001 for further details). Then, in order to clarify if the SW events not simultaneous to cyclones could be related to the orographic interaction, these events (the $36 \%$ of the total number of SW events) are cross-referenced with this high-resolution cyclone database. Results show that in most of those events $(84.9 \%$ of this subset of events, i.e. the $30.5 \%$ total set of SW events) a small-scale low pressure centre is found. These lows are mainly located at the south of the Pyrenees (see Fig. 3). These low-pressure centres are small and non-intense, and probably linked with the orographic interaction.

Only for a small number of events, an intense Atlantic cyclone (then located out of the study area and so not included into the cyclone database) could be related to the SW in Catalonia.

\subsection{Heavy rain-strong wind and cyclones}

For almost all the HR-SW events $(87.5 \%)$, a cyclone is found. Moreover, most of them are located very close, to the south of Catalonia, in the same area where a high fre- 


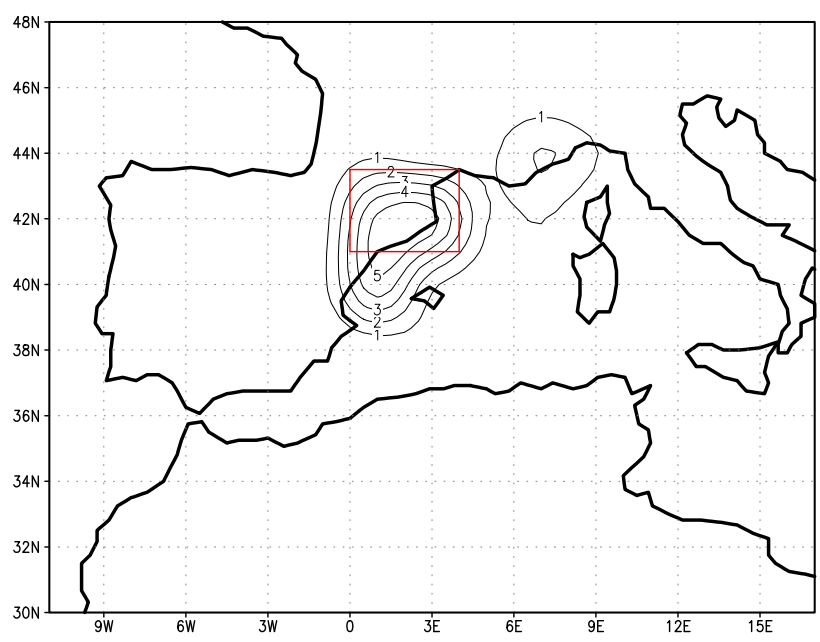

Fig. 3. Relative frequency (in $2^{\circ} \times 2^{\circ}$ latitude-longitude boxes) of cyclones (non-smoothed cyclone database) simultaneous to SW events without a simultaneous cyclone in the smoothed database. Contour interval: $1 \%$.

quency of cyclones is found for both HR and SW separately (see Fig. 4).

Most of these cyclones are deep (see Table 1). Besides, these low pressure centres are more intense and larger than the simultaneous to HR events, although less intense than the simultaneous to SW events (see Table 2).

This type of events are very often related to severe weather in Catalonia. The 9-10 June of 2000 floods caused 5 casualties, landslides, buildings and roads destroyed, and as a result damages for more than 72 millions of euros. Heavy rain was registered on the 9th and 10th, and strong wind on the 10th. The role of the low level cyclone near the coast has been underlined in some studies (López and Aran, 2004).

\section{Discussion}

As it was previously mentioned, for the $77.5 \%$ of the HR events occurred in Catalonia a cyclone was found. However, the presence of a cyclone close to Catalonia is also large anytime $(56.9 \%)$. Furthermore, these cyclones are quite similar (in location, thickness, intensity ...) to the formers. Hence other factors, as the availability of moisture or the upper-level forcing, must be also involved. Moreover, the important seasonal signal of HR also points in this line. In autumn the Mediterranean is a pool of warm and moist air (usually potentially unstable) and then certain cyclones could contribute to produce HR, while similar cyclones (but with less moisture available) in another season probably not.

On the contrary, the relationship between cyclones and $\mathrm{SW}$ events is not as large as expected. The percentage of simultaneity between an intense (weighted value) cyclone and

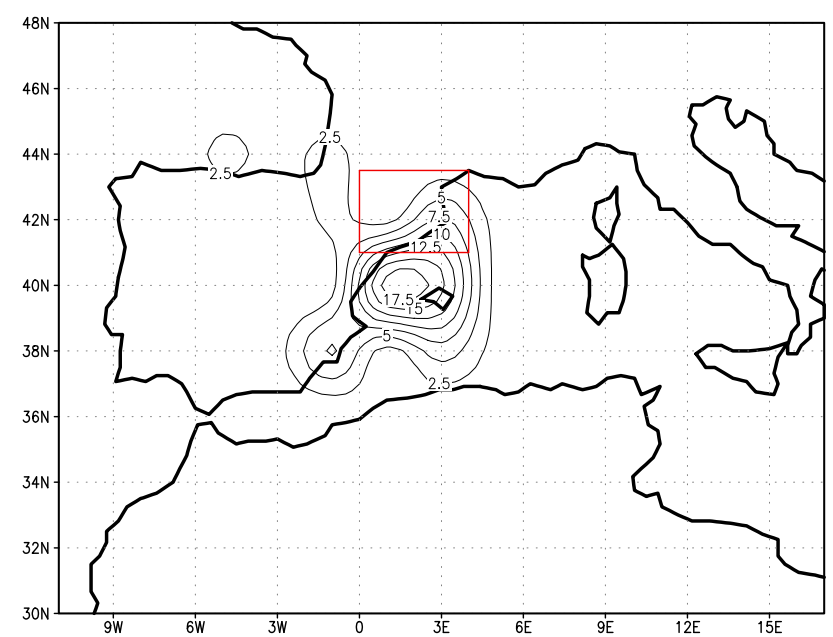

Fig. 4. Relative frequency (in $2^{\circ} \times 2^{\circ}$ latitude-longitude boxes) of the closest cyclone simultaneous to HR-SW events. Contour interval: $2.5 \%$.

the strong wind is high, clearly higher than for the whole study period. However, for an important number of strong wind events no cyclone was found. In fact strong wind can be produced not only by strong pressure gradients linked to cyclones, but also by mesoscale phenomena as local winds or convective gusts. The presence of the Pyrenees induces the generation of local winds, as the Tramontane and the Mestral, which could be responsible for most of the strong wind events non-related to cyclones.

\section{Conclusions}

High impact weather (heavy rain and strong wind) in Catalonia and a cyclone database have been cross-referenced to look for simultaneity. In most of the heavy rain events (77.5\%) cyclones have been found close to Catalonia, and furthermore in a such a way as to feed with moist and warm air the heavy rain areas.

Many strong wind events $(64 \%)$ are related to a simultaneous cyclone. These cyclones are, on one hand, strong lows located around the gulf of Genoa, and on the other hand cyclones at the south of Catalonia, and then much more close.

Acknowledgements. The authors acknowledge R. Romero and an anonymous reviewer for their comments and suggestions that have helped to improve the contents and clarity of the Manuscript. The authors also thank the contribution of J. Cunillera, N. Pineda and M. Prohom from the Meteorological Service of Catalonia.

Edited by: P. Alpert, H. Saaroni, and E. Heifetz Reviewed by: two anonymous referees 


\section{References}

Bessemoulin, P., Bougeault, P., Genovés, A., Jansà, A., and Puech, D.: Mountain pressure drag during PYREX, Beitr. Phys. Atmosph., 66, 305-325, 1993.

Bougeault, P., Benech, B., Bessemoulin, P., Carissimo, B., Jansà, A., Pelon, J., Petitdidier, M., and Richard, E.: PYREX: Summary of findings, Bull. Am. Meteorol. Soc., 78, 637-650, 1997.

Buzzi, A., D'Isidoro, M., and Davolio, S.: A case-study of an orographic cyclone south of the Alps during the MAP SOP, Q. J. Roy. Meteor. Soc., 129, 1795-1818, 2003.

Campins, J., Jansà, A., Benech, B., Koffi, E., and Bessemoulin, P.: PYREX observation and model diagnosis of the tramontane wind, Meteorol. Atmos. Phys., 56, 209-228, 1995.

Campins, J., Jansà, A., and Genovés, A.: Heavy rain and strong wind events and cyclones in the Balearics, Adv. Geosci., 7, 7377, 2006, http://www.adv-geosci.net/7/73/2006/.

Campins, J., Jansà, A., and Genovés, A.: Three-dimensional structure of Western Mediterranean cyclones, Int. J. Climatol., 26, 323-343, 2006.

Horvath, K., Fita, L., Romero, R., Ivancan-Picek, B., and Stiperski, I.: Cyclogenesis in the lee of the Atlas Mountain: a factor separation numerical study, Adv. Geosci., 7, 327-331, 2006, http://www.adv-geosci.net/7/327/2006/.

Homar, V., Romero, R. Ramis, C., and Alonso, S.: Numerical study of the October 2000 torrential precipitation event over eastern Spain: analyses of the synoptic scale stationarity, Ann. Geophys., 20, 2047-2066, 2002,

http://www.ann-geophys.net/20/2047/2002/.
Jansà, A., Genovés, A., Picornell, M. A., Campins, J., Riosalido, R., and Carretero, O.: Western Mediterranean cyclones and heavy rain. Part 2: Statistical approach, Meteorol. Appl., 8, 43-56, 2001.

Llasat, M. C.: Gota fría, Editorial Boixareu Universitaria, Ciencias, No. 6, (in Spanish), Barcelona, 1991.

López, J. M. and Aran, M.: Estudio de una ciclogénesis rápida mediterranea: Cataluña, 9-10 de junio de 2000, Nota Técnica del CMT de Cataluña, Instituto Nacional de Meteorología, 2004.

Pascual, R. and Callado, A.: Mesoanalysis of recurrent convergence zones in the north-eastern Iberian Peninsula, Proceedings of the ERAD-2002, 59-64, 2002.

Picornell, M. A., Jansà, A., Genovés, A., and Campins, J.: Automated database of mesocyclones from the HIRLAM(INM- $0.5^{\circ}$ ) analyses in the Western Mediterranean, Int. J. Climatol., 21, 335354, 2001.

Riosalido, R., Vázquez, L., Gordo, A., and Jansà, A.: Cierzo: Northwesterly wind along the Ebro Valley(Spain) as a mesoscale effect induced on the lee of the Pyrenees mountain range; a case study during the Alpine Experiment(ALPEX) Special Observing Period, WMO Proceedings of the Conference on the Scientific Results of the Alpine Experiment(ALPEX), Vol. 2, 565-575, GARP Publications Series No. 27, WMO/TD No. 108, 1986.

Romero, R., Sumner, G., Ramis, C., and Genovés, A.: A classification of the atmospheric circulation patterns producing significant daily rainfall in the Spanish Mediterranean area, Int. J. Climatol., 19, 765-785, 1999. 